\title{
The gastric cardia in gastro-oesophageal disease
}

\author{
Hala M T El-Zimaity, Vino J Verghese, Jacqueline Ramchatesingh, David Y Graham
}

\begin{abstract}
Background-There have been conflicting reports concerning the use of cardia biopsies in screening patients for gastrooesophageal disease.

Aim-To define the histopathological changes in the gastric cardia of patients with and without gastro-oesophageal disease.

Methods-Topographically mapped gastric biopsy specimens were obtained from patients with gastro-oesophageal disease and from controls. Biopsies were scored on a visual analogue scale of 0 to 5 for Helicobacter pylori, intestinal metaplasia, pancreatic metaplasia, foveolar hyperplasia, and active inflammation. The presence or absence of cardiac glands was recorded.
\end{abstract}

Results-Sixty five patients with gastrooesophageal disease and 71 controls were examined. Intestinal metaplasia was present in cardia biopsies of 10 patients with gastro-oesophageal disease and 11 controls. Only two patients with gastrooesophageal disease and intestinal metaplasia in the cardia had no evidence of exposure to $\mathrm{H}$ pylori. Intestinal metaplasia was not found in the cardia of those with long segment Barrett's oesophagus. Carditis was strongly associated with active $H$ pylori infection $(p=0.000)$ and resolved after treatment of the infection. A negative association was present between gastro-oesophageal disease and the presence of cardiac glands in cardiac biopsies $(p=0.003)$. Pancreatic metaplasia was found in 15 of 65 and foveolar hyperplasia in 19 of 65 cases but neither was related to gastro-oesophageal disease.

Gastrointestinal

Mucosa Pathology

Laboratory, Room

3A352, Veterans Affairs

Medical Center

(111-D), 2002

Holcombe Blvd,

Houston, Texas 77030 ,

USA

H M T El-Zimaity

$\mathrm{J}$ Ramchatesingh

Department of

Medicine, Veterans

Affairs Medical Center

and Baylor College of

Medicine, Houston,

Texas, USA

V J Verghese

D Y Graham

Correspondence to:

Dr El-Zimaity

email:

hzimaity@bcm.tmc.edu

Accepted for publication

7 March 2000

In the past decade, there has been increased interest in Barrett's oesophagus. ${ }^{1-4}$ The criteria for the diagnosis of Barrett's epithelium has been revised from requiring at least $3 \mathrm{~cm}$ of specialised columnar epithelium above the oesophago-gastric junction to any specialised columnar epithelium above the oesophagogastric junction. ${ }^{2}$ This change in thinking was prompted by studies suggesting that the presence of specialised columnar epithelium in tongues of red mucosa extending above the $\mathrm{Z}$ line might be more properly considered as short segment Barrett's oesophagus. ${ }^{5}$ Biopsies below the $\mathrm{Z}$ line were also reported to show specialised columnar epithelium in some patients and the question arose as to whether this also represented another form of short segment Barrett's oesophagus, ${ }^{5-9}$ or whether it was related to a more generalised atrophic process in the stomach. ${ }^{10-14}$

Recent studies have largely solved this dilemma. The most comprehensive study prospectively evaluated 110 cases with specialised intestinal metaplasia in the gastric cardia. ${ }^{15}$ Patients with flat $\mathrm{Z}$ lines (the squamocolumnar junction and the oesophago-gastric junction present at the same level) were examined separately from patients with eccentric $\mathrm{Z}$ lines (tongues of red mucosa extended into the oesophagus) and from patients with classic long segment Barrett's oesophagus. Specialised columnar epithelium below the $\mathrm{Z}$ line (in the gastric cardia) was not associated with either short or long segment Barrett's oesophagus. These and other recent studies have shown that specialised columnar epithelium (called intestinal metaplasia when it is elsewhere in the stomach) is largely, but not exclusively, a reflection of the effect of Helicobacter pylori infection of the gastric mucosa, with intestinal metaplasia usually also being present in the antrum and/or corpus. ${ }^{10-14}$

Published studies have focused primarily on the presence or absence of intestinal metaplasia in the cardia, with little regard to other histopathological correlates that might provide additional diagnostic or prognostic information. Our study was prompted by our impression that foveolar hyperplasia was more common in the cardia of patients with gastro-oesophageal disease than in those without. Therefore, we examined gastric biopsies from the cardia in a large number of patients with and without gastro-oesophageal disease to examine features related to gastro-oesophageal disease and/or $\mathrm{H}$ pylori infection. Biopsies were categorised in relation to $H$ pylori, intestinal metaplasia, neutrophilic infiltration, foveolar hyperplasia, pancreatic metaplasia, as well as the presence of cardiac glands and oxyntic glands.

\section{Methods}

PATIENTS AND ENDOSCOPY

Cases were selected retrospectively from more than 1000 patients of all ethnic groups both with and without $H$ pylori infection examined by the gastrointestinal mucosa pathology laboratory at Baylor College of Medicine between 1992 and 1997. Simple gastric mapping 
typically involved taking 14 biopsies from specified sites and this was done on more than 200 patients. Cardiac and gastric mucosal biopsies (ranging from two to 29/patient) were obtained by one gastroenterologist (DYG) from specific gastric sites. Biopsies of the gastric cardia (mean and median, 2) were always taken antegrade within $0.5 \mathrm{~cm}$ of the $\mathrm{Z}$ line or oesophago-gastric junction in those with long segment Barrett's oesophagus.

We chose specimens from 136 patients to represent the spectrum of gastro-oesophageal disease. The primary selection factors were the presence of at least two large cup biopsies from the gastric cardia, and a clear cut history of the presence (or absence) of gastro-oesophageal disease. Patients were stratified after endoscopy. Barrett's oesophagus was defined as the presence of columnar appearing mucosa in the distal oesophagus at upper endoscopy, with intestinal metaplasia on biopsy. Patients with short segment Barrett's oesophagus were excluded from our study.

Patients with gastro-oesophageal disease were classified into five grades according to the criteria of Savary and Miller. ${ }^{16}$ All charts were reviewed. Patients who had been taking medication such as acid suppressing drugs, antibiotics, and/or bismuth within the two month before examination were excluded from our study. The charts of all control patients were re-reviewed to ensure that those with symptoms suggestive of gastro-oesophageal disease were excluded. The control group included normal volunteers and family members of patients with gastric cancer, as well as those with a variety of gastroduodenal diseases, such as gastric mucosal associated lymphoid tissue (MALT) lymphoma, lymphocytic gastritis, non-steroidal anti-inflammatory drugs (NSAID) associated gastric ulcer, duodenal ulcer, and patients with a previous diagnosis of intestinal metaplasia.

\section{HISTOLOGY}

Each biopsy was placed in a separate bottle of $10 \%$ buffered formalin. Biopsies were embedded on edge, sectioned at $5 \mu \mathrm{m}$, with six sections/slide, and stained with the Genta stain ${ }^{17}$ or El-Zimaity triple stain. ${ }^{18}$ The median size of biopsy specimens (measured on a glass slide) was $8 \times 4 \mathrm{~mm}$. A visual analogue scale from 0 (absent/normal) to 5 (maximal intensity) $^{19}$ was used by one pathologist (HE-Z) to grade the following histological features: H pylori, intestinal metaplasia, neutrophils, foveolar hyperplasia, and pancreatic metaplasia (defined as small nests or nodules of pancreatic acinar cells). Intestinal metaplasia was subtyped into complete and incomplete using high iron diamine, according to the

Table 1 Clinical features

\begin{tabular}{|c|c|c|c|c|c|}
\hline & All controls & Volunteers & $\begin{array}{l}\text { GERD score } \\
(0-1)\end{array}$ & $\begin{array}{l}\text { GERD score } \\
(2-3)\end{array}$ & $\begin{array}{l}\text { GERD score } \\
(4-5)\end{array}$ \\
\hline Number & 71 & 23 & 23 & 30 & 12 \\
\hline Age (years) & $\begin{array}{l}23-81 \\
\text { (median, 60) }\end{array}$ & $\begin{array}{l}24-79 \\
\text { (median, 52) }\end{array}$ & $\begin{array}{l}34-76 \\
\text { (median, 56) }\end{array}$ & $\begin{array}{l}28-70 \\
\text { (median, 51) }\end{array}$ & $\begin{array}{l}35-75 \\
\text { (median, 62) }\end{array}$ \\
\hline Sex & $9 \mathrm{~F}, 62 \mathrm{M}$ & $9 \mathrm{~F}, 14 \mathrm{M}$ & $1 \mathrm{~F}, 22 \mathrm{M}$ & $1 \mathrm{~F}, 29 \mathrm{M}$ & $12 \mathrm{M}$ \\
\hline
\end{tabular}

GERD, gastro-oesophageal disease; F, female; $M$, male.
Table 2 Histological features in the gastric cardia

\begin{tabular}{llll}
\hline Feature & $\begin{array}{l}\text { GERD } \\
(n=65)\end{array}$ & $\begin{array}{l}\text { Controls } \\
(n=71)\end{array}$ & $p$ Value \\
\hline Foveolar hyperplasia & $19(29 \%)$ & $15(19 \%)$ & 0.24 \\
Carditis & $25(38 \%)$ & $32(45 \%)$ & 0.48 \\
Cardiac mucosa only & $37(57 \%)$ & $57(80 \%)$ & 0.005 \\
Intestinal metaplasia & $10(15 \%)$ & $11(16 \%)$ & 1 \\
Pancreatic metaplasia & $15(27 \%)$ & $23(32 \%)$ & 0.56 \\
\hline
\end{tabular}

GERD, gastro-oesophageal disease.

system used by Jass and Filipe. ${ }^{20}{ }^{21}$ In addition, the type of mucosa in each cardiac biopsy (cardiac glands $v$ oxyntic) was documented. Carditis was defined as glandular infiltration with polymorphonuclear leucocytes.

\section{HELICOBACTER PYLORI STATUS}

Most cases had been evaluated according to our routine protocol for $H$ pylori assessment, ${ }^{22}$ which includes a biopsy from the greater curve of the distal antrum and the midcorpus as well as a biopsy from the gastric angle. This approach is essentially $100 \%$ accurate at identifying $H$ pylori status. ${ }^{22}{ }^{23}$ In most patients, a lesser curve antral biopsy and a greater curve corpus biopsy were also taken for culture. All cases were confirmed as $H$ pylori positive or negative based on the consistency of these tests. Histological evidence of past $H$ pylori infection was defined as a past history, and was based on either a previous biopsy documenting the infection, presence of organised lymphoid follicles ${ }^{24}{ }^{25}$ in tissue sections, or positive serology for antibodies against $H$ pylori.

STATISTICAL ANALYSES

All scores were entered into a database and analysed using Sigma Stat 2.03 (SPSS, Chicago, Illinois, USA). Fisher's exact test or, when appropriate, the $\chi^{2}$ test (both two tailed) were used for comparison of proportions. The significance of differences and relations was determined by $\mathrm{p}$ values of less than 0.05 .

\section{Results}

Gastric mucosal biopsies from 136 patients were studied ( 125 men, 11 women) including 65 with gastro-oesophageal disease and 71 without clinical or endoscopic evidence of this disease. In the gastro-oesophageal disease group, the Savary-Miller score was 0 to 1 in 23, 2 to 3 in 30, and 4 to 5 in 12. Only patients with long segment Barrett's oesophagus were included in our study. Table 1 shows the clinical features of the patients included.

A total of 1081 slides was examined: 288 from the cardia (median, 2), 315 from the antrum (median, 3), and 478 from the corpus (median, 1). Tables 2 and 3 summarise the prevalence of the evaluated histological features and their respective scores.

FOVEOLAR HYPERPLASIA

Contrary to our prestudy impression, there was no difference in the prevalence of foveolar hyperplasia in the cardia between those with gastro-oesophageal disease and controls; 19 of 65 with gastro-oesophageal disease compared with 15 of 71 of controls $(p=0.24)$. 
Table 3 Histological features in the gastric cardia as it relates to Helicobacter pylori status

\begin{tabular}{llll}
\hline Feature & $\begin{array}{l}\text { H pylori positive, active } \\
\text { and cured }(n=116)\end{array}$ & $\begin{array}{l}\text { H pylori negative } \\
(n=20)\end{array}$ & p Value \\
\hline Foveolar hyperplasia & $31(27 \%)$ & $3(15 \%)$ & 0.4 \\
Cardiac mucosa only & $86(74 \%)$ & $8(40 \%)$ & 0.004 \\
Oxyntic mucosa only & $16(14 \%)$ & $8(40 \%)$ & 0.009 \\
Pancreatic metaplasia & $38(33 \%)$ & $1(5 \%)$ & 0.008 \\
\hline
\end{tabular}

There was no relation between the presence of foveolar hyperplasia in the cardia biopsies and active $H$ pylori infection $(\mathrm{p}=0.8)$. Foveolar hyperplasia was identified in cardia biopsies of 34 patients, 16 had active $H$ pylor $i$ infection and 18 were negative for infection $(p=0.8)$. Similarly, no correlation was found when active and previous infection were analysed. Of 18 patients negative for active $H$ pylori infection, 14 had organised lymphoid follicles suggesting past $H$ pylori infection. Of four patients negative for active $H$ pylori infection, and any histopathological features suggestive of previous exposure, sera were available from three; one was positive for H pylori $(\mathrm{p}=0.4)($ table 3$)$.

CARDITIS

We defined carditis as glandular infiltration with polymorphonuclear leucocytes. Carditis was present in cardia biopsies of 57 patients; 32 without gastro-oesophageal disease and 25 with the disease $(\mathrm{p}=0.48)$. Forty six patients had active $H$ pylori infection and carditis was present in all 46. Follow up biopsies from the cardia were available in seven patients who were cured of the infection, and in all instances it resolved, confirming that carditis usually reflects $H$ pylori infection.

Carditis was also found in those without active $H$ pylori infection (11 of 90 patients: $\mathrm{p}>0.001$ for carditis with $v$ without $H$ pylori infection). On a visual analogue of 0 to 5 , the median score of active inflammation in carditis without active $H$ pylori infection was 2 compared with a median score of 3 in patients with active $H$ pylor $i$ infection. The clinical diagnosis of the 11 patients was MALT lymphoma in four, gastric ulcer in two, and lymphocytic gastritis, gastric polyp, gastric cancer, gastrooesophageal disease, and normal in one patient each. Only one had no evidence of past $H$ pylori infection and serum was not available for analysis.

CARDIAC VERSUS OXYNTIC MUCOSA IN THE GASTRIC CARDIA

Histological examination of two biopsy specimens of the cardia revealed cardiac glands in 114 patients (84\%); it was present in both biopsies in 94 patients (69\%) and in only one of the two biopsies in 18 patients. Twenty four $(16 \%)$ had fundic (oxyntic) epithelium only and in nine of 40 biopsies with oxyntic glands at least one of the biopsies also contained the squamo-columnar junction, confirming that the biopsy was from the gastric cardia.

There was a significant negative association between the presence of cardiac mucous glands in both cardiac biopsies and gastrooesophageal disease (57 of 71 controls $v 37$ of 65 with gastro-oesophageal disease; $p=0.005$; table 2). The presence of cardiac mucous glands in both biopsies was also associated with $H$ pylori infection (active or past); both cardiac biopsies had cardiac glands in 86 of the 116 patients exposed to $H$ pylori compared with 8 of the 20 patients without previous exposure $(p=0.004)$ (table 3$)$. The presence of cardiac glands in both biopsies also correlated with the presence of intestinal metaplasia elsewhere in the stomach; 53 of 94 had intestinal metaplasia elsewhere in the stomach compared with two of 24 patients with oxyntic mucosa only in the two cardia biopsies $(p=0.000)$. Overall, these results suggest that the size of the cardia, and thus the likelihood of obtaining biopsies containing only cardiac glands, was related to the presence of $H$ pylori infection. Because cardiac mucosa is a transitional epithelium, one would anticipate that it might mirror the transition of the antrum and corpus. The absence of oxyntic glands in both large cup biopsies of the cardia might represent mild atrophy of the oxyntic mucosa.

\section{INTESTINAL METAPLASIA}

Intestinal metaplasia in the cardia was closely but not exclusively related to $H$ pylori infection (current or previous) ( $\mathrm{p}>0.001)$. For example, in the control group, all 11 patients with intestinal metaplasia in the cardia had been previously exposed to $H$ pylori. Nine also had intestinal metaplasia in other parts of the stomach. Among the gastro-oesophageal disease group, 10 patients had intestinal metaplasia in the cardia and eight had evidence of exposure to $H$ pylori and had intestinal metaplasia in other parts of the stomach. Two of the 65 patients with gastro-oesophageal disease (3\%; 95\% confidence interval, $0.4 \%$ to $10.5 \%$ ) did not have active $H$ pylori infection and did not have histopathological changes suggestive of previous exposure, such as intestinal metaplasia or organised lymphoid follicles, ${ }^{24}{ }^{25}$ in other parts of the stomach. A serum sample from one of the patients was available for testing for $H$ pylori antibodies and it was negative. The Savary-Miller score for these two patients was 0 and 3. There were only five patients with Savary-Miller score 3 or 4; one had intestinal metaplasia in the cardia. Of 13 patients with Barrett's oesophagus (Savary-Miller grade 5), none had intestinal metaplasia in the cardia. On evaluating the value of subtyping intestinal metaplasia as a pre-neoplastic marker no difference was found between the two groups of patients. Eight control patients and seven with gastro-oesophageal disease had complete intestinal metaplasia in their cardia biopsies $(p=1.0)$. The ethnic group was known in 18 of the 21 patients with intestinal metaplasia in the cardia: five were black, five were Hispanic, and eight were white. All were men.

INTESTINAL METAPLASIA IN THE CORPUS AND GASTRO-OESOPHAGEAL DISEASE

There was an inverse relation between the presence of gastro-oesophageal disease and intestinal metaplasia in the gastric corpus. Corpus biopsies were available from 75 control patients and 56 patients with gastrooesophageal disease, and intestinal metaplasia 
was found in $27 \%$ of control patients compared to $1 \%$ of patients with gastro-oesophageal disease $(p>0.001)$. Thus, patients with gastrooesophageal disease had the least atrophy in their stomach.

\section{PANCREATIC METAPLASIA}

There was no relation between the presence of pancreatic metaplasia and gastro-oesophageal disease because 15 of 38 patients with pancreatic metaplasia had gastro-oesophageal disease (15 of 65) compared with 23 of 71 controls $(p=0.56)$. Pancreatic metaplasia was strongly associated with $H$ pylor $i$ infection because 36 of 38 patients with cardia pancreatic metaplasia had $H$ pylori infection (active or cured). The presence of pancreatic metaplasia was not correlated with the presence of intestinal metaplasia elsewhere in the stomach (intestinal metaplasia elsewhere in the stomach was found in $38 \%$ of those with pancreatic metaplasia compared with $46 \%$ without; $p=0.46)$. The median ages for patients with pancreatic acinar metaplasia and controls were the same (57 years).

COMPARISON WITH VOLUNTEERS ONLY

The results with the volunteers were similar to those of the entire control group without gastro-oesophageal disease. Gastric mucosal biopsies from 23 volunteers studied (14 men, nine women) were evaluated separately to ensure that the results with the entire group were representative. Table 4 summarises the prevalence of the evaluated histological features. Volunteers were on average younger and all had either active $H$ pylori infection or a history of infection. Intestinal metaplasia was less frequent than in the controls as a group, but the difference was not significant $(17 \% v 16 \%$; $\mathrm{p}=1.0)$.

ANALYSIS WITH CASES LIMITED TO THOSE WITH SQUAMOCOLUMNAR JUNCTION IN THE BIOPSY Gastric mucosal biopsies from 51 patients (26 with gastro-oesophageal disease and 25 without) were from the $\mathrm{Z}$ line and had both squamous and columnar tissue present. Carditis was present in the cardia of 20 patients $(10$ with gastro-oesophageal disease and 10 without). Eighteen had active $H$ pylori infection. Of the two without an active infection, the score for polymorphonuclear leucocytes was 1 and 2, respectively. Intestinal metaplasia was closely but not exclusively related to $H$ pylori infection (current or past). The four in the control group with intestinal metaplasia in the cardia had been previously exposed to $H$ pylori and three had intestinal metaplasia in other parts of the stomach. Eight patients with gastro-

Table 4 Histological features in the gastric cardia of volunteers

\begin{tabular}{llllll}
\hline Feature & $\begin{array}{l}\text { GERD } \\
(n=65)\end{array}$ & $\begin{array}{l}\text { Control } \\
\text { non-volunteers } \\
(n=48)\end{array}$ & $p$ Value & $\begin{array}{l}\text { Volunteers } \\
(n=23)\end{array}$ & p Value \\
\hline Foveolar hyperplasia & $19(29 \%)$ & $12(25 \%)$ & 0.7 & $3(13 \%)$ & 0.2 \\
Carditis & $25(38 \%)$ & $19(40 \%)$ & 1 & $13(57 \%)$ & 0.1 \\
Cardiac mucosa only & $37(57 \%)$ & $40(83 \%)$ & 0.000 & $17(74 \%)$ & 0.2 \\
Intestinal metaplasia & $10(15 \%)$ & $7(15 \%)$ & 1 & $4(17 \%)$ & 1 \\
Pancreatic metaplasia & $15(27 \%)$ & $16(33 \%)$ & 0.7 & $7(30 \%)$ & 1 \\
\hline
\end{tabular}

oesophageal disease had intestinal metaplasia in the cardia, seven had evidence of previous exposure to $H$ pylori, and five had intestinal metaplasia in other parts of the stomach. One patient (Savary-Miller score, 0) had intestinal metaplasia in the cardia and did not have histopathological changes suggestive of previous exposure. The patient's serum was not available for testing for $H$ pylori antibodies.

There was no difference in the prevalence of foveolar hyperplasia and pancreatic metaplasia in those with gastro-oesophageal disease compared with the control group. Nine of 25 patients without gastro-oesophageal disease and seven of 26 patients with the disease had foveolar hyperplasia in the cardia biopsies $(p=0.6)$. Pancreatic metaplasia was present in 11 patients without gastro-oesophageal disease and eight with the disease $(p=0.4)$. The association between the presence of cardiac mucous glands in both biopsies and gastrooesophageal disease was not observed when the analysis was limited to this group of patients (79\% of controls $v 63 \%$ of patients with gastro-oesophageal disease; $\mathrm{p}=0.4$ ).

\section{Discussion}

The recent $^{26}$ increase in gastro-oesophageal junction carcinomas ${ }^{27-30}$ has raised concerns regarding the best method for identifying Barrett's mucosa. Spechler et al suggested that intestinal metaplasia in the cardia is most commonly part of gastro-oesophageal disease and a form of short segment Barrett's oesophagus. ${ }^{5}$ This hypothesis has not been confirmed because most studies have supported the notion that intestinal metaplasia in the gastric cardia is most often related to H pylori infection..$^{10-14}$ The fact that intestinal metaplasia in the cardia is not exclusively associated with $H$ pylori infection is exemplified by the studies of Hirota and colleagues ${ }^{15}$ and Hackelsberger et $a l b^{31}$ who reported that intestinal metaplasia in the cardia could be a manifestation of $H$ pylori infection and can also be associated with gastro-oesophageal disease independent of $H$ pylori. None of our patients with documented long segment Barrett's oesophagus had intestinal metaplasia in the gastric cardia. This is similar to the finding of Hirota, who found intestinal metaplasia in the cardia of only $1.6 \%$ of patients with Barrett's oesophagus. ${ }^{15}$ Together, these observations provide strong evidence against intestinal metaplasia in the cardia being a precursor of typical long segment Barrett's oesophagus.

As with other studies, ${ }^{10-14}$ we found a strong association between intestinal metaplasia in the cardia and $H$ pylori infection associated intestinal metaplasia elsewhere in the stomach. This finding is stronger than it appears, given the patchy nature of intestinal metaplasia in the stomach, and the low likelihood that a single biopsy of the greater curvature of the midcorpus would discover it. ${ }^{23}$ Nevertheless, two patients with intestinal metaplasia in the cardia had no evidence of active or past exposure to $H$ pylori; one had a gastro-oesophageal disease score of 3, and the second had a gastrooesophageal disease score of 4 ; both were 


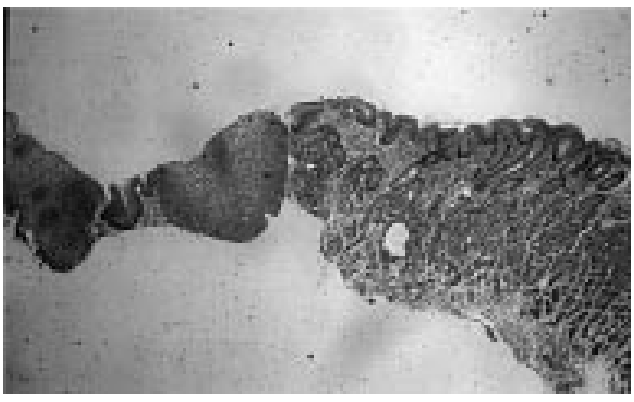

Figure 1 The cardia is a small structure varying from 0-10 mm in length. El-Zimaity triple stain. Original magnification, $\times 4$.

white. Our study differed from previous studies evaluating the cardia in that we evaluated patients' sera and other areas in the stomach for the presence of $H$ pylori and $H$ pylori stigmata. Other investigators who noted intestinal metaplasia in the cardia unrelated to $H$ pylori infection have also noted that it appeared to be associated with the more severe grades of oesophagitis. ${ }^{5}{ }^{15} 31-33$

We speculate that some of the confusion regarding short segment Barrett's and intestinal metaplasia of the cardia $^{5-14}$ is related to sampling technique, to the definitions used, and to the prevalence of $H$ pylori in the population studied. The cardia is a small structure varying from about 0 to $10 \mathrm{~mm}$ in length (mean, 3) ) $^{34-37}$ (fig 1). Oberg et al, who used either the antegrade or the retrograde technique of biopsy, found histological cardiac mucosa most often in the presence of a hiatal hernia. We believe that antegrade biopsy is important if one is to sample the cardia reliably. The presence of a hiatal hernia makes antegrade biopsy and positioning of the forceps adjacent to the $\mathrm{Z}$ line easy, whereas positioning the forceps adjacent to the $\mathrm{Z}$ line in the retrograde position is much more difficult, and might explain some of the differences between studies. ${ }^{9}$

In the study by Spechler et $a l,{ }^{5}$ all patients with intestinal metaplasia in the cardia were white and there was a preponderance of men. It is not clear whether their results occurred by chance because their study population had a low background incidence of $H$ pylori. Other investigators, ${ }^{7533}$ as well as our data, show no sex or ethnic specificity relating to the presence of intestinal metaplasia in the cardia. Overall, we believe the data support a dual pathogenic mechanism for intestinal metaplasia in the cardia, ${ }^{1531}$ with $H$ pylori infection playing a major role. In our series, intestinal metaplasia of the gastric cardia secondary to gastrooesophageal disease was uncommon and, as noted above, was not found in patients with long segment Barrett's oesophagus.

Although intestinal metaplasia in the cardia is not a form of short segment Barrett's oesophagus, it might still represent a risk of cancer. The cancer risk is for gastric cancer unrelated to gastro-oesophageal disease. The presence of intestinal metaplasia in the cardia was related to intestinal metaplasia elsewhere in the stomach, suggesting that these patients are at a higher risk for developing $H$ pylori related gastric cancer. The real risk to patients with intestinal metapla- sia in the cardia of developing cardia carcinoma can only be answered with long term prospective studies. In Hirota and colleagues' study of 47 patients with intestinal metaplasia at the oesophago-gastric junction, ${ }^{15}$ two had low grade dysplasia, and one had a small adenocarcinoma in the cardia. The status of other regions of the stomach was not evaluated in their study because only two biopsies were taken from below the squamo-columnar junction. No sex or ethnic specificity has been identified in patients with intestinal metaplasia at the gastrooesophageal junction. None of the patients in our series with intestinal metaplasia in the cardia developed carcinoma (median follow up period, four years).

Although most investigators have focused on the presence of intestinal metaplasia, our study examined other histopathological correlates in the cardia in relation to gastro-oesophageal disease and $H$ pylori infection. Carditis defined as the presence of glandular infiltration with polymorphonuclear cells was closely but not exclusively related to active $H$ pylori infection. Carditis in patients with $H$ pylori infection disappeared when patients were cured of the infection. We also found no relation between cardiac foveolar hyperplasia and gastrooesophageal disease or $H$ pylori infection (active or past). In contrast, Oberg et al, ${ }^{9}$ who equated foveolar hyperplasia with carditis, reported an association with a structurally defective lower oesophageal sphincter. Differences between the two studies relate to sampling techniques and to the fact that Oberg et al evaluated no non-gastro-oesophageal disease control group. ${ }^{9}$

Pancreatic metaplasia was defined as small nests or variably sized nodules of pancreatic acinar cells and has been suggested to be a metaplastic change in response to chronic atrophic gastritis, ${ }^{38} 39$ a congenital feature, ${ }^{40-42}$ or both. We found a strong correlation between pancreatic acinar metaplasia and $H$ pylori infection and no correlation was present with intestinal metaplasia elsewhere in the stomach. Although the presence of pancreatic acinar cells in two infants can be explained as an aberration of stem cell differentiation, ${ }^{40}$ chronic $H$ pylori infection may potentially result in aberrant differentiation of gastric epithelium (for example, formation of intestinal metaplasia). A similar, but different, pathogenic mechanism might also play a role in pancreatic metaplasia formation.

The negative association of gastrooesophageal disease with the presence of cardiac mucous glands in both cardiac biopsies is of particular interest. Traditionally, the stomach has been divided into three zones. Although there is overlap between regions, the body and fundus contain oxyntic mucosa comprised of parietal (oxyntic) cells, chief cells, and mucous neck cells. The antrum and the cardia region contain mucous glands, which are called cardiac glands when they are present in the cardia. ${ }^{43}$ The presence and extent of mucous glands in the antrum increases with $H$ pylori infection. ${ }^{44}$ Our data suggest that the size of the region containing cardiac glands is relatively 
smaller in patients with gastro-oesophageal disease. The presence of gastro-oesophageal disease requires that the patients secrete sufficient acid to cause damage, and these patients are less likely to have widespread gastric atrophy. The presence of cardiac glands in both cardiac biopsies was strongly associated with $H$ pylori infection (active or past) $(\mathrm{p}=0.004)$. With chronic exposure to $H p y-$ lori, the junction between the corpus and antrum changes and the antrum expands in a pyloro-cardial direction. ${ }^{44}$ Our data suggest that a similar process occurs at the cardiacorpus junction, but in the opposite direction (antral). This hypothesis is supported by the strong association between the presence of cardiac glands in both biopsies and the presence of intestinal metaplasia elsewhere in the stomach $(\mathrm{p}=0.005)$.

The perceived increase in oesophageal and cardiac adenocarcinoma ${ }^{27-30}$ may represent changes in the diagnosis, classification, and reporting of cancer in this region of the stomach, ${ }^{26}$ as well as a real increase in the frequency of adenocarcinoma in this location. ${ }^{45}{ }^{46}$. Thus, it is important to identify appropriate health care measures that result in cost effective early disease detection and intervention. Our study does not support a role for routinely obtaining cardiac biopsies in screening patients with gastro-oesophageal disease for the presence of Barrett's oesophagus. Interpretation of intestinal metaplasia in the cardia requires consideration of the status of the gastric mucosa elsewhere in the stomach. Patients with intestinal metaplasia in the cardia might represent a group with more severe atrophy in the stomach and thus with a higher risk for developing $H p y$ lori related gastric cancer. Although intestinal metaplasia in the cardia should not be considered as a form or precursor to Barrett's oesophagus, at this time its risk for progression to carcinoma is not definitely known.

This work was supported by the Department of Veterans Affairs and by NIH grant DK53659, as well as the generous support of Hilda Schwartz.

1 el-Serag HB, Sonnenberg A. Ethnic variations in the occurrence of gastroesophageal cancers. I Clin Gastroenterol 1999;28:135-9.

2 Falk GW. Reflux disease and Barrett's esophagus. Endoscopy 1999;31:9-16.

3 Eloubeidi MA, Provenzale D. Does this patient have Barrett's esophagus? The utility of predicting Barrett's esophagus at the index endoscopy. Am 7 Gastroenterol 1999;94:937-43.

4 Henihan RDJ, Stuart RC, Nolan N, et al. Barrett's esophagus and the presence of Helicobacter pylori. $A m$ f Gastroenterol 1998;93:542-6.

5 Spechler SJ, Zeroogian JM, Antonioli DA, et al. Prevalence of metaplasia at the gastro-oesophageal junction. Lancet of metaplasia at the

6 Chalasani N, Wo JM, Hunter JG, et al. Significance of intestinal metaplasia in different areas of esophagus including esophagogastric junction. Dig Dis Sci 1997;42:603-7.

7 Voutilainen M, Farkkila M, Juhola M, et al. Specialized columnar epithelium of the esophagogastric junction prevalence and associations. Am $\mathcal{F}$ Gastroenterol 1999;94: 913-18.

8 Pereira AD, Suspiro A, Chaves P, et al. Short segments of Barrett's epithelium and intestinal metaplasia in normal appearing oesophagogastric junctions: the same or two different entities? Gut 1998;42:659-62.

9 Oberg S, Peters JH, DeMeester TR, et al. Inflammation and specialized intestinal metaplasia of cardiac mucosa is a manifestation of gastroesophageal reflux disease. Ann Surg 1997;226:522-30; discussion 530-2.

10 Morales TG, Sampliner RE, Bhattacharyya A. Intestinal metaplasia of the gastric cardia. Am $\mathcal{f}$ Gastroenterol 1997;92:414-18.
11 Hackelsberger A, Gunther T, Schultze V, et al. Prevalence and pattern of Helicobacter pylori gastritis in the gastric and pattern of Helicobacter pylori gastritis
cardia. Am 7 Gastroenterol 1997;92:2220-4.

12 Goldblum JR, Vicari JJ, Falk GW, et al. Inflammation and intestinal metaplasia of the gastric cardia: the role of gastroesophageal reflux and $\mathrm{H}$ pylori infection. Gastroenterology 1998;114:633-9.

13 el-Serag HB, Sonnenberg A, Jamal MM, et al. Characteristics of intestinal metaplasia in the gastric cardia. Am f Gastroenterol 1999;94:622-7.

14 Craanen ME, Blok P, Dekker W, et al. Helicobacter pylori and early gastric cancer. Gut 1994;35:1372-4.

15 Hirota WK, Loughney TM, Lazas DJ, et al. Specialized intestinal metaplasia, dysplasia, and cancer of the esophagus and esophagogastric junction: prevalence and clinical gus and esophagogastric junction: prev

16 Ollyo JB, Fontolliet CH, Brossard E, et al. Savary's new endoscopic classification of reflux esophagitis. Acta Endoscopica 1992;22:307-20.

17 Genta RM, Robason GO, Graham DY. Simultaneous visualization of Helicobacter pylori and gastric morphology: a new stain. Hum Pathol 1994;25:221-6.

18 El-Zimaity HMT, Ota H, Scott S, et al. A new triple stain for Helicobacter pylori suitable for the autostainer. Arch Pathol Lab Med 1998;122:732-6.

19 El-Zimaity HM, Graham DY, Al-Assi MT, et al. Interobserver variation in the histopathological assessment of Helicobacter pylori gastritis. Hum Pathol 1996;27:35-41.

20 Rokkas T, Filipe MI, Sladen GE. Detection of an increased incidence of early gastric cancer in patients with intestinal incidence of early gastric cancer in patients with intestinal
metaplasia type III who are closely followed up. Gut 1991; 32:1110-13.

21 Silva S, Filipe MI, Pinho A. Variants of intestinal metaplasia in the evolution of chronic atrophic gastritis and gastric ulcer. A follow up study. Gut 1990;31:1097-104

22 El-Zimaity HM, Al-Assi MT, Genta RM, et al. Confirmation of successful therapy of Helicobacter pylori infection: number and site of biopsies or a rapid urease test. $A m \mathcal{F}$ Gastroenterol 1995;90:1962-4.

23 El-Zimaity HMT, Graham DY. Evaluation of gastric mucosal biopsy site and number for identification of Helicobacter pylori or intestinal metaplasia: role of the Sydney system. Hum Pathol 1999;30:72-7.

24 Genta RM, Hamner HW. The significance of lymphoid follicles in the interpretation of gastric biopsy specimens. Arch Pathol Lab Med 1994;118:740-3.

25 Genta RM, Hamner HW, Graham DY. Gastric lymphoid follicles in Helicobacter pylori infection: frequency, distribution and response to triple therapy. Hum Pathol 1993;24: 577-83

26 Ekstrom AM, Signorello LB, Hansson L-E, et al. Evaluating gastric cancer misclassification: a potential explanation for the rise in cardia cancer incidence. F Natl Cancer Inst 1999; 91:786-90.

27 Antonioli DA, Goldman H. Changes in the location and type of gastric adenocarcinoma. Cancer 1982;50:775-81.

28 Blot WJ, Devesa SS, Kneller RW, et al. Rising incidence of adenocarcinoma of the esophagus and gastric cardia. adenocarcinoma of the

29 Pera M, Cameron AJ, Trastek VF, et al. Increasing incidence of adenocarcinoma of the esophagus and esophagogastric junction. Gastroenterology 1993;104:510-13.

30 Craanen ME, Dekker W, Blok P, et al. Time trends in gastric carcinoma: changing patterns of type and location. Am $\mathcal{F}$ Gastroenterol 1992;87:572-9.

31 Hackelsberger A, Gunther T, Schultze V, et al. Intestinal metaplasia at the gastro-oesophageal junction: Helicobacter pylori gastritis or gastro-oesophageal reflux disease? Gut 1998;43:17-21.

32 Nandurkar S, Talley NJ, Martin CJ, et al. Short segment Barrett's oesophagus: prevalence, diagnosis and associations. Gut 1997;40:710-15.

33 Weston AP, Krmpotich PT, Cherian R, et al. Prospective evaluation of intestinal metaplasia and dysplasia within the cardia of patients with Barrett's esophagus. Dig Dis Sci 1997;42:597-602.

34 Krause WJ, Ivey KJ, Baskin WN, et al. Morphological observations on the normal human cardiac glands. Anat $\operatorname{Rec}$ 1978;192:59-72.

35 Bensley RR. The cardiac glands of mammals. Am f Anat 1902;2:105-56.

36 Miyagawa Y. The exact distribution of the gastric glands in man and in certain animals. F Anat 1921;55:56-67.

37 Takubo K, Mafune K, Tanaka Y, et al. Pathology of the cardia. Nippon Geka Gakkai Zasshi 1998;99:547-51.

38 Stachura J, Konturek J, Urbanczyk K, et al. Pancreatic metaplasia of the human gastric mucosa is associated with high expression of transforming growth factor alpha but not of epidermal growth factor. Histopathology 1995;27: $509-15$.

39 Doglioni C, Laurino L, Dei Tos AP, et al. Pancreatic (acinar) metaplasia of the gastric mucosa. Am $\mathcal{f}$ Surg Pathol 1993;17:1134-43.

40 Luque-Barona RJ, Pereda-Salguero T, Fernandez-Alonso J. So-called pancreatic acinar metaplasia of the gastric mucosa in two infants: a post-mortem study [letter]. Eur $\mathcal{F}$ Pediatr 1999;158:267-8.

41 Integlia MJ, Krishnamurthy S, Berhane R, et al. Pancreatic metaplasia of the gastric mucosa in pediatric patients. Am $\mathcal{F}$ Gastroenterol 1997;92:1553-6.

42 Wang HH, Zeroogian JM, Spechler SJ, et al. Prevalence and significance of pancreatic acinar metaplasia at the gastroesophageal junction. Am $\mathcal{F}$ Surg Pathol 1996;20:1507-10. 
43 Owen DA. Stomach. In: Sternberg SS, ed. Histology for pathologists, 2nd ed. Philadelphia: Lippincott-Raven, 1997:

44 Kimura K. Chronological transition of the fundic-pyloric border determined by stepwise biopsy of the lesser and greater curvatures of the stomach. Gastroenterology 1972; 63:584-92.
45 el-Serag HB, Sonnenberg A. Opposing time trends of peptic ulcer and reflux disease. Gut 1998;43:327-33.

46 Kumagai T, Malaty HM, Graham DY, et al. Acquisition versus loss of Helicobacter pylori infection in Japan: results from an 8-year birth cohort study. F Infect Dis 1998;178: $717-21$ 